\title{
p53-Dependent and -Independent Functions of the Arf Tumor Suppressor
}

\author{
C.J. Sherr, ${ }^{* \dagger}$ D. Bertwistle, ${ }^{* \dagger}$ W. Den Besten, ${ }^{\dagger}$ M.-L. Kuo, ${ }^{* \dagger}$ M. Sugimoto, ${ }^{* \dagger}$ K. Tago, ${ }^{\dagger \dagger}$ \\ R.T. Williams ${ }^{\dagger \dagger}$ F. ZindY ${ }^{\dagger}$ AND M.F. Roussel ${ }^{\dagger}$ \\ *Howard Hughes Medical Institute and Departments of ${ }^{\dagger}$ Genetics and Tumor Cell Biology and \\ ${ }^{*}$ Hematology-Oncology, St. Jude Children's Research Hospital, Memphis, Tennessee 38105
}

\begin{abstract}
The Ink4a-Arf locus encodes two closely wedded tumor suppressor proteins (p16 ${ }^{\text {Ink4a }}$ and $\mathrm{p} 19^{\text {Arf }}$ ) that inhibit cell proliferation by activating $\mathrm{Rb}$ and $\mathrm{p} 53$, respectively. With few exceptions, the Arf gene is repressed during mouse embryonic development, thereby helping to limit p53 expression during organogenesis. However, in adult mice, sustained hyperproliferative signals conveyed by somatically activated oncogenes can induce Arf gene expression and trigger a p53 response that eliminates incipient cancer cells. Disruption of this tumor surveillance pathway predisposes to cancer, and inactivation of INK4a$A R F$ by deletion, silencing, or mutation has been frequently observed in many forms of human cancer. Although it is accepted that much of Arf's tumor-suppressive activity is mediated by p53, more recent genetic evidence has pointed to additional p53independent functions of Arf, including its ability to inhibit gene expression by a number of other transcription factors. Surprisingly, the enforced expression of Arf in mammalian cells promotes the sumoylation of several Arf-interacting proteins, implying that Arf has an associated catalytic activity. We speculate that transcriptional down-regulation in response to Arfinduced sumoylation may account for Arf's p53-independent functions.
\end{abstract}

Mammalian INK4 proteins are specific polypeptide inhibitors of the cyclin D-dependent kinases (Cdk4 and Cdk6) whose expression helps to maintain proteins of the retinoblastoma family (RB, p107, and p130) in their active hypophosphorylated states. By doing so, the INK4 proteins enhance the growth-suppressive activities of RB and its relatives, thereby preventing cells from entering the DNA synthetic (S) phase of the cell division cycle and reinforcing RB-dependent transcriptional programs that regulate cell differentiation and senescence. The founding member of the INK4 gene family, INK4a (Serrano et al. 1993), is one of four genes whose encoded products act in a biochemically similar manner to inhibit the $\mathrm{Cdk} 4$ and Cdk6 kinases (Roussel 1999; Ortega et al. 2002). In humans, INK4a and $I N K 4 b$ are closely linked on the short arm of chromosome 9 , whereas the two other family members $(I N K 4 c$ and $I N K 4 d)$ reside on chromosomes 1 and 19, respectively. In the mouse, however, Ink $4 a$, Ink $4 b$, and $I n k 4 c$ all map to chromosome 4 with Ink $4 c$ separated from the Ink $4 a / I n k 4 b$ cluster by $18 \mathrm{cM}$. The Ink4c and Ink $4 d$ genes are ubiquitously expressed in highly stereotypic patterns in the mouse embryo, and their loss of function can severely compromise the proper development of certain tissues. In contrast, neither Ink $4 a$ nor Ink $4 b$ is expressed during development or, at appreciable levels, in tissues of young mice (Zindy et al. 1997, 2003), and their inactivation in the germ line does not lead to obvious developmental anomalies (Serrano et al. 1996; Latres et al. 2000; Krimpenfort et al. 2001; Sharpless et al. 2001). Instead, their induction occurs in response to particular cellular stresses that can contribute to tumor formation (Lowe and Sherr 2003). At least three Ink4 proteins (p16 $6^{\text {Ink4a }}, \mathrm{p} 15^{\text {Ink4b }}$, and $\mathrm{p} 18^{\text {Ink4c }}$ ) are tumor suppressors, but by far, the most frequently inactivated family member in human cancers is INK4a (Ruas and Peters 1998).
Remarkably, the mouse Ink4a locus was found to encode yet another tumor suppressor protein, $19^{\text {Arf }}$ (p14 ${ }^{\mathrm{ARF}}$ in humans) whose expression induces $\mathrm{p} 53$ (Quelle et al. 1995; Kamijo et al. 1997). The organization of the locus - now designated Ink4a-Arf - is unusual in the sense that the two protein products are encoded in part by alternative reading frames (from which $\operatorname{Arf}$ takes its name) within exon 2 (Fig. 1A). Because the Ink $4 a$ and Arf genes have alternative first exons and separate promoter elements, they can be independently regulated, mutated, and epigenetically silenced. Together, INK4a, $A R F, R B$, and TP53 represent the most frequently inactivated tumor suppressors in human tumors, suggesting that their loss of function might be a necessary prerequisite for the transformation of normal cells into cancer cells. Here, we review $A r f$ 's activities and discuss insights stemming from recent studies.

\section{p19 ${ }^{\text {Arf }}$ INDUCES p53-THE ORIGINAL PARADIGM}

Enforced expression of the p19 ${ }^{\text {Arf }}$ protein arrests cells in both the $G_{1}$ and $G_{2}$ phases of the cell division cycle (Quelle et al. 1995). Much of the growth-suppressive function of $199^{\text {Arf }}$ depends on its ability to interfere with the p53 negative regulator Mdm2 (HDM2 in humans), which itself is a p53-responsive gene. Arf stabilizes p53 by blocking Mdm2's activity as an E3 ubiquitin protein ligase (Honda and Yasuda 1999). It can also relocalize Mdm2 into nucleoli, where the bulk of intracellular p19 ${ }^{\text {Arf }}$ resides (Weber et al. 1999), although this may not be necessary for p53 induction (Llanos et al. 2001). Whatever the exact mechanisms involved, growth arrest by $\mathrm{p} 19^{\mathrm{Arf}}$ depends to a great extent on p53-dependent transcription, which up-regulates many antiproliferative 
A.

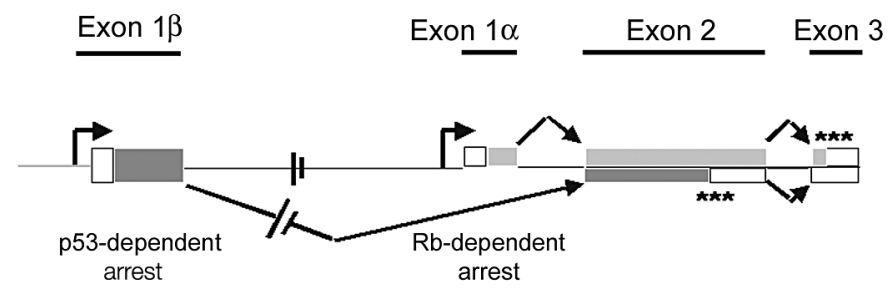

B.

$4 \quad 8 \quad 13$

23

47

54

Hs MVRRFLVTLRIRR--ACGPPRVRVFVVHIPRLTGEWAAPGAPAAVALVLMLLRSQR-LGQQ

Mm MGRRFLVTVRIQR--AGRPLQERVFLVKFVRSRRPRTASCALAFVNMLLRLERILR-RGPH

Md MIRRVRVTVRVSR--ACRPHHVRIFVAKIVQALCRASAS INQGTPFQVLLIVRKKRHRGRS

Rn MGRREVVTVRIRR--TGRSPQVRVFLVQFLGSSRPRSANGTRGFVALVLRPERIAR-RGPQ

SS MVRRLLITVRIRR--SCGPPRVRAFVVQIARPAGEWAAPGVRAAAARVLLLVRSQR-RAQQ

Ma MGRRFVVTVRIRRRRADRPPRVRAFVVQFPRSSRHRSASRARAVVALLLMLARSQRQRGPR

Gg MTSRIRCTVCLRR--A-RS-RPLSFSLLRRILRGVAAVLRRSGTLRRILRRVLRRRHRGSR

Figure 1. Organization of the Ink4a-Arf locus and comparison of amino acid sequences encoded by Arf exon $1 \beta$ in various species. (A) The Ink $4 a$ gene is composed of three exons $(1 \alpha, 2$, and 3 indicated by boxes). Coding segments are indicated by light gray shading above the horizontal line whereas noncoding segments are unshaded. The $\operatorname{Arf}$ gene is represented by exons $1 \beta(\sim 15 \mathrm{~kb}$ upstream), 2 , and 3. Coding sequences (dark gray shading) in exon 2 are in an alternative reading frame from that which encodes p16 $6^{\text {Ink4a }}$. Arrows indicate the two promoters and splicing patterns. Asterisks denote the positions of termination codons. Strains of knockout (KO) mice include animals that lack both gene products (Serrano et al. 1996), Arf alone (Kamijo et al. 1997), and Ink4a alone (Krimpenfort et al. 2001; Sharpless et al. 2001). Sequences encoding GFP have also been knocked into (KI) the Arf locus replacing exon $1 \beta$ (Zindy et al. 2003). (B). Amino-terminal sequences encoded by Arf exon 1( from Homo sapiens (Hs), Mus musculus (Mm), Monodelphis domestica (opossum) (Md), Ratus norvegicus (Rn), Sus scrofa (domestic pig) (Ss), Mesocricetus auratus (golden hamster) (Ma), and Gallus gallus (chicken) (Gg). The positions of six universally conserved residues are denoted by bold type and by numbers above the figure. (Adapted, with permission, from Sherr [1998] and Kuo et al. [2004].)

genes, such as the Cdk inhibitor p21 ${ }^{\text {Cip } 1}$ (El-Deiry et al. 1993), as well as a subset of genes that contribute to p53's pro-apoptotic functions (Vousden and Lu 2002). However, p19 ${ }^{\text {Arf }}$ can arrest the division of cells lacking Cip1 (Pantoja and Serrano 1999; Modestou et al. 2001) as well as those lacking $p 53$ alone or both $p 53$ and $M d m 2$, albeit much less efficiently than in cells that preserve $\mathrm{p} 53$ function (Carnero et al. 2000; Weber et al. 2000b). Thus, Arf has both p53-dependent and -independent activities.

Animals lacking Arf are highly tumor-prone, although spontaneous tumors occur with a rate and spectrum that differ from those of animals lacking $p 53$ (Jacks et al. 1994; Kamijo et al. 1999a). Whereas $p 53$-null mice tend to develop lymphomas and die within 6 months of birth, the Arf-null animals live much longer (up to 15 months) and have a propensity to develop more sarcomas than lymphomas. In addition, about $25 \%$ of Arf-null animals develop gliomas and carcinomas, which rarely arise spontaneously in mice lacking $p 53$. Although $A r f$ is activated in response to various forms of stress (see below), it is not acutely induced in response to DNA double-strand breaks triggered by ionizing irradiation, although $A r f$ 's absence can enhance Mdm2's ability to down-regulate p53 during the DNA damage response (Kamijo et al. 1997, 1999b). Triple knockout (TKO) mice lacking $A r f, M d m 2$, and $p 53$ rapidly develop many more tumors - and frequently, multiple tumors of different histological types per animalthan mice lacking both $M d m 2$ and $p 53$ (Weber et al. $2000 \mathrm{~b}$ ). Indeed, most TKO animals die of various cancers before reaching breeding age. Although obtained with difficulty, TKO mouse embryonic fibroblasts (MEFs) can be growth-arrested when $\mathrm{p} 19^{\text {Arf }}$ expression is reinforced. Together, these results underscore the ability of $\mathrm{p} 19^{\text {Arf }}$ to interact with targets other than Mdm2 and p53.

\section{Arf REGULATES REPLICATIVE SENESCENCE}

Although $A r f$ is expressed in the yolk sac and embryonic eye (see below), it is not appreciably expressed in other tissues within the mouse embryo, implying that the Arf-Mdm2-p53 pathway is generally shut off during development in utero (Zindy et al. 1997, 2003). However, explantation and passage of primary MEFs in tissue culture leads to Arf induction with a steady increase in its protein levels that correlates with the waning proliferative capacity of continuously propagated cells (Kamijo et al. 1997; Zindy et al. 1998). This seemingly spontaneous activation of $\mathrm{p} 19^{\mathrm{Arf}}$ in cultured MEFs results in their replicative senescence. Conversely, MEFs explanted from Arf-null animals not only proliferate faster than their wild-type counterparts in culture, but also do not senesce and behave like established mouse cell lines (Kamijo et al. 1997). Moreover, immortalized cell populations that arise stochastically as wild-type MEFs are continuously propagated in culture either acquire $p 53$ mutations (Harvey and Levine 1991) or sustain bi-allelic Ink4a-Arf deletions (Kamijo et al. 1997). These findings pointed to the idea that Ink $4 a$ and Arf are induced in response to the nonphysiological tissue culture milieu ("culture shock") (Sherr and DePinho 2001). The rate of Arf induction can be accelerated by introducing oncogenes such as activated Myc, Ras, or adenovirus E1A into primary cell strains (Zindy et al. 1998; De Stanchina et al. 1998; Palmero et al. 1998) or by subjecting MEFs to low but persistent levels of oxidative stress (Busuttil et al. 2003; Parrinello et al. 2003). Ink4a is also induced by many of the same stress stimuli that impinge upon $A r f$, but even though $\mathrm{p} 16^{\text {Ink4a }}$ levels continue to rise to a maximum during continuous passage of MEFs in 
culture, Ink4a loss alone in MEFs does not bypass senescence (Krimpenfort et al. 2001; Sharpless et al. 2001). Still, the determinants of the senescence response of mouse cells are to some extent cell-type-specific. For example, bonemarrow-derived pre-B cells can be immortalized through Arf inactivation, whereas immortalization of bone-marrow-derived macrophages explanted from Arf-null animals depends on the inactivation of Ink4a, which undergoes epigenetic silencing (Randle et al. 2001).

The co-inactivation of INK4a and ARF (or co-elimination of both $R B$ and TP53) endows human cells with an increased cellular life span in culture. However, these events are not sufficient to immortalize human cells in which replicative senescence is also triggered by telomere malfunction (Wright and Shay 2000). MEFs have considerably longer telomeres than those of human fibroblast strains, and they have a greater propensity to express telomerase and maintain telomere length. Engineered acute disruption of mouse telomere integrity activates the Arf checkpoint, whereas both $A R F$ and $I N K 4 a$ respond in human cells (Smogorzewska and De Lange 2002). On the basis of these and other considerations, it has been suggested that INK4a may play a more significant role in governing the senescence of human versus mouse cells (Wright and Shay 2000). By genetically eliminating telomerase activity in the mouse germ line and interbreeding the progeny, later generations of telomerase-null mice that developed shorter telomeres were forced to confront the problem of telomere insufficiency (Blasco et al. 1997). Cells from these "humanized" mouse strains not only activated Rb- and p53-dependent checkpoints in response to telomere shortening but, in the absence of these checkpoints, manifested progressive telomere attrition and eventually entered "crisis" (Lee et al. 1998; Rudolph et al. 1999). The latter event is characterized by end-to-end chromosome fusions and fusion-bridge-breakage cycles that destabilize the genome and trigger mitotic catastrophe. Because cells from these mice cannot reactivate telomerase activity, they can only restabilize their telomeres through alternative recombination-based mechanisms. Mice lacking telomerase and intact checkpoint controls spontaneously develop a telling spectrum of tumors, the majority of which are carcinomas that are rarely observed in wild-type mice (Artandi et al. 2000). This response to checkpoint disruption and telomere attrition closely reflects the human cancer condition in which carcinomas predominate as we age.

\section{ACTIVATING $\operatorname{Arf}$ GENE EXPRESSION}

Abnormal hyperproliferative signals conveyed by oncogenes can remodel the otherwise insulated Arf promoter to enable its expression (Lowe and Sherr 2003). In turn, the ability of $\mathrm{p} 19^{\text {Arf }}$ to activate $\mathrm{p} 53$ provides a safeguard that protects such cells from oncogenic challenge. In a Burkitt's lymphoma model in which a Myc transgene is driven by an immunoglobulin promoter-enhancer (E $\mu$ Myc mice) (Adams et al. 1985), Arf induction in Myc-expressing B cells limits Myc's pro-proliferative effects early in the course of disease. However, continued Myc expression eventually selects for the appearance of cells that have sustained p53 mutations or Arf deletions, thereby allowing lymphomas to arise (Eischen et al. 1999; Jacobs et al. 1999b; Schmitt et al. 1999). Eu-Mycinduced lymphomagenesis is greatly accelerated in an $A r f^{+/}$genetic background where the wild-type $A r f$ allele is rapidly inactivated; in an $A r f^{-/}$background, animals become moribund very soon after birth, and all die within 8 weeks of highly aggressive lympholeukemias with widespread visceral involvement (Eischen et al. 1999). Similar effects of Arf on tumor suppression have been observed in carcinogen-induced skin tumors where somatic mutation of Ras is the initiating step (Kelly-Spratt et al. 2004). Importantly, Myc or Ras signaling in normal cells, although important for their proliferative response to mitogens, is insufficient to activate Arf. Therefore, Arf acts as a fuse to monitor mitogenic "current" and to trigger a p53 response only when mitogenic signals are abnormally sustained and/or elevated above a potentially deleterious threshold level.

Strikingly, after replacement of Arf exon $1 \beta$ genomic sequences with those encoding green fluorescent protein (GFP), tumors arising in functionally $\mathrm{Arf}$-null $\mathrm{Arf}$ GFP/GFP homozygous mice were vividly fluorescent, whereas the non-tumor tissues in moribund mice did not express GFP (Fig. 2A,B,D) (Zindy et al. 2003). When the Eu-Myc transgene was expressed in $A r f^{\mathrm{GFP} /+}$ heterozygotes, the wild-type allele was lost and lymphomagenesis was accelerated relative to the rate of tumor formation in $\mathrm{Arf}^{+/+}$

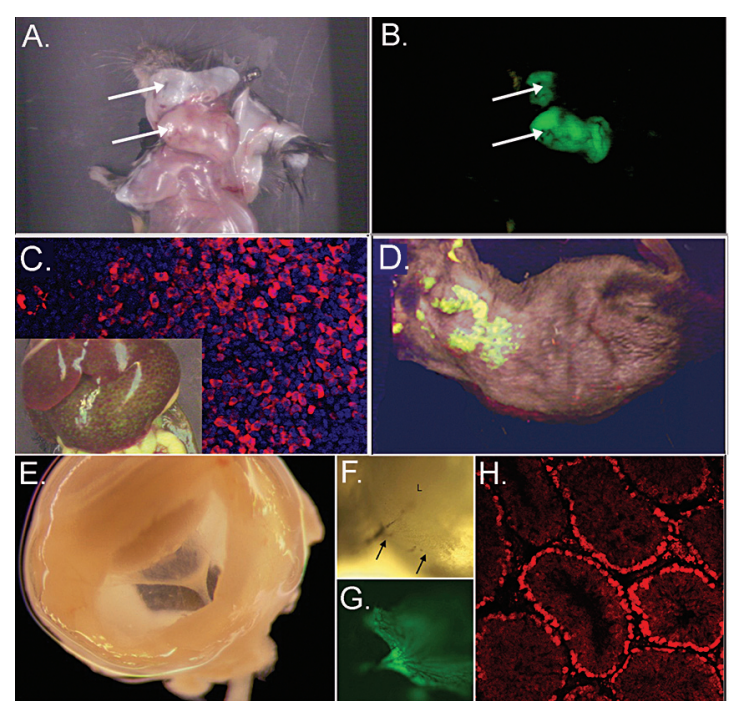

Figure 2. GFP expression in tissues of $A r f$ GFP/GFP mice. $(A, B)$ A green fluorescent fibrosarcoma in the neck region. $(C)$ Macroscopic foci of GFP-positive lymphoma cells in the liver and a microscopic metastasis (inset) visualized by immunofluorescence (red) and counterstained with 4',6-diamidino2-phenylindole (blue). (D) Whole-body imaging of a shaved $\mathrm{Arf}^{+/ \mathrm{GFP}}$ E $\mu-M y c$ transgenic mouse with lymphoma. $(E)$ Whole mount showing a funnel-shaped mass stretching from the lens (top left) toward the optic cup (rear). A closer view shows elements of the hyaloid vasculature $(F$, arrows) within the fluorescent mass $(G)$. $(H)$ Immunohistochemical staining of GFP $(r e d)$ in the testis of an 8-month-old mouse. (Reprinted, with permission, from Zindy et al. 2003.) 
littermates. Early in the course of disease, we detected GFP-positive cells in the bone marrow, spleen, and lymph nodes of E $\mu-M y c$ transgenic Arf ${ }^{\mathrm{GFP} /+}$ mice, implying that Arf induction could be used to monitor precancerous lesions. In turn, once lymphomas arose, their metastatic spread was marked by the appearance of vividly fluorescent tumor nodules in various organs (Fig. 2C). Using a monoclonal antibody to $\mathrm{p} 19^{\text {Arf }}$ that detects the endogenous protein in fixed lymphoid cells (Bertwistle et al. 2004b), we hope to determine how early in the course of E $\mu$-Myc-induced disease the endogenous Arf protein is induced.

Interestingly, with few exceptions, very few cells in young, normal Arf ${ }^{\text {GFP/GFP }}$ homozygotes exhibited green fluorescence. However, Arf-null mice become blind soon after birth due to the formation of a cellular mass in the vitreous that disrupts the normal architecture of the lens and retina. Arf expression in the vitreous during the first week after birth is required for regression of the hyaloid vasculature system that nourishes the developing lens (McKeller et al. 2002). In newborn Arf-null mice, persistence of the hyaloid vasculature leads to an abnormal proliferation of perivascular cells that form a funnel-shaped mass in the vitreous (Fig. 2E,F). In $\operatorname{Arf}^{\text {GFP/GFP }}$ animals, the retrolental mass included green fluorescent cells (Fig. 2G). Arf expression could also be observed in testicular tubules, in cells that most likely represent spermatogonia or leptotene spermatocytes at the earliest stages of meiosis I (Fig. 2H). Small pockets of green fluorescent cells could be seen in other ostensibly normal tissues, including the thymic medulla and lung alveoli, although such cells were rare and expressed only low levels of GFP detected by immunohistochemistry (Zindy et al. 2003).

Understanding how the Arf promoter distinguishes normal and abnormal signaling thresholds remains problematic. Arf is normally repressed by E2F complexes (Rowland et al. 2002), but unlike many E2F-responsive genes that govern DNA synthesis and replication, Arf is not periodically expressed when cells enter $\mathrm{S}$ phase. Yet, when Arf is induced by oncogenes, E2Fs 1, 2, and 3a replace repressive E2F complexes on the Arf promoter (Aslanian et al. 2004). Hence, other specificity factors must play a role in modulating this E2F response. An attractive candidate is the Dmp1 transcription factor, which binds adjacent to an E2F site in the proximal Arf promoter to activate the gene (Inoue et al. 1999). Several features suggest that Dmp1 plays a role in regulating Arf induction mediated by oncogenes: (1) Dmpl is a Ras-responsive gene that is activated via the Raf-MEK-ERK pathway (Sreeramaneni et al. 2005); (2) Dmpl overexpression in response to oncogenic Ras induces cell cycle arrest in primary MEFs in an Arf-dependent manner (Inoue et al. 1999); (3) conversely, Dmpl-null MEFs bypass senescence with relative ease and can be transformed even at early passage by oncogenic Ras at a detectable frequency (Inoue et al. 2000); (4) $D m p 1^{-/-}$and $D m p 1^{+/-}$mice, like Arf-null animals, are highly sensitive to E $\mu-M y c$ - or carcinogen-induced lymphomagenesis, and in these settings, Dmpl is haplo-insufficient for tumor suppression; (5) inactivation of Dmpl reduces the frequency of Arf loss and p53 mutation during E $\mu-M y c$-induced lymphomagenesis, indicating that Dmpl is a genetic modifier of the Arf-Mdm2-p53 signaling pathway (Inoue et al. 2001). It will be of interest to determine the status of various E2F complexes on the Arf promoter in cells lacking Dmpl and in those reconstituted with wild-type and mutant Dmpl alleles.

Arf is subject to repression by a variety of other proteins, including Bmi1, Tbx2 and Tbx3, Jun D, Twist, CBX7, and Pokemon (Jacobs et al. 1999b, 2000; Maestro et al. 1999; Weitzman et al. 2000; Lingbeek et al. 2002; Gil et al. 2004; Maeda et al. 2005). Some of these repressors are likely to be responsible for silencing the Arf locus during development. In particular, inactivation of Bmil results in inappropriate Ink4a-Arf expression in cerebellar granule neuron precursors and in adult hematopoietic stem cells, so that Bmil-null animals exhibit defects in postnatal cerebellar development and die early in life from bone marrow aplasia. These defects are rescued on an Ink4a-Arf-null background, indicating that abnormal activation of the locus can interfere with these developmental processes (Jacobs et al. 1999a). In contrast, multiple embryonic defects arising in mice lacking Twist (W. den Besten, unpubl.) or yolk sac atresia occurring in homozygous Tbx3-null mice (Jerome-Majewska et al., in press) are not rescued in an Arf-null background.

\section{THE p19 ${ }^{\text {Arf }}$ PROTEIN: A CHALLENGE FOR BIOCHEMISTS}

Arf proteins are highly basic $(\mathrm{pI} \sim 12)$ and contain $\sim 20 \%$ arginine but only one (p19 $9^{\mathrm{Arf}}$ ) or no $\left(\mathrm{p} 14^{\mathrm{ARF}}\right)$ lysines. Truncation of the mouse Arf gene near the exon $1 \beta$-exon 2 junction yielded a polypeptide of 64 amino acids that exhibited the growth-suppressing activity of the parental full-length molecule (Quelle et al. 1997). In this regard, chickens lack the Ink4a locus but have an Arf gene specifying a 7-kD protein encoded almost exclusively by exon $1 \beta$ sequences (Fig. 1B) (Kim et al. 2003). Most recombinant $\mathrm{p} 19^{\mathrm{Arf}}$ protein expressed in bacteria is insoluble, and many arginyl codons are improperly translated. Reasoning that the more abundant species of bacterial arginyl tRNAs do not efficiently recognize a subset of mammalian arginine codons, we used synthetic oligonucleotides to construct an Arf minigene encoding the amino-terminal 62 amino acids of p19 $19^{\text {Arf }}$; in doing so, many codons were altered to improve translation in bacteria (Weber et al. 2000a). Although the correct product was produced, much of it remained insoluble and worthless for "test tube biochemistry" or for structural analysis.

Given the fact that Arf proteins must function at neutral $\mathrm{pH}$, they must be highly buffered within living cells. Using tandem affinity-tagged p19 ${ }^{\text {Arf }}$, we purified Arf-associated proteins from mouse fibroblasts undergoing cell cycle arrest and identified them by mass spectroscopy. TAPtagged Arf associated with many proteins, the most prominent being nucleophosmin (NPM/B23), an abundant and highly acidic nucleolar protein (Bertwistle et al. 2004a). Although only a small fraction of cellular NPM binds to p19 ${ }^{\text {Arf }}$, most of the Arf protein in cells is associated with NPM, and this interaction occurs equally well in primary cells lacking Mdm2 and p53. When p19 Arf expression is induced, it colocalizes with NPM in very high molecular 
weight complexes of 2-5 MD. The biological meaning of the Arf-NPM interaction remains unclear. One group of investigators suggested that $\mathrm{p} 19^{\text {Arf }}$ can impede NPM nucleocytoplasmic shuttling (Brady et al. 2004), whereas others have argued that NPM helps to sequester p19 Arf in nucleoli (Korgaonkar et al. 2005). All agree that $\mathrm{p} 19^{\text {Arf }}$ binds NPM through the same domains that mediate its binding to $\mathrm{Mdm} 2$, so that the latter two proteins can compete with one another for $\mathrm{p} 19^{\text {Arf }}$ binding. When associated with NPM, $\mathrm{p} 19^{\text {Arf }}$ is highly stable and turns over with a half-life of 6-8 hours (Kuo et al. 2004). Overexpression of NPM further slows p19 Arf turnover, whereas "knocking down" NPM with shRNA has the opposite effect. An Arf mutant lacking amino-terminal residues $2-14$ or another in which alanines were substituted for all six conserved residues encoded by exon $1 \beta$ (Fig. 1B) still localized to nucleoli but did not bind with high affinity to either Mdm2 or NPM and was handicapped in inducing growth arrest. These two mutant proteins turn over with half-lives of only 90-120 minutes (Kuo et al. 2004). Thus, the stoichiometric binding of p19 ${ }^{\text {Arf }}$ to nucleolar NPM might enable Arf to fold into a stable conformation, whereas unbound p19 ${ }^{\text {Arf }}$ mutants might be aberrantly folded and subject to more rapid degradation.

The absence of lysine residues in human $\mathrm{p} 14^{\mathrm{ARF}}$ implied that its turnover did not depend on ubiquitination. However, both mouse $\mathrm{p} 19^{\text {Arf }}$ and human $\mathrm{p} 14^{\mathrm{ARF}}$ undergo amino-terminal ubiquitination and proteasomal degradation (Kuo et al. 2004). Most eukaryotic proteins are acetylated at their amino termini and are therefore not substrates for amino-terminal ubiquitination. $\mathrm{N}$-acetylation is favored by the presence of amino-terminal methionine, which can be cleaved by methionine aminopeptidase when the penultimate amino acid has a small radius of gyration (Bradshaw et al. 1998). Proteolytic exposure of certain amino-terminal residues, such as serine, allows acetylation to proceed efficiently, whereas other amino acids, such as glycine, are poor substrates (Polevoda and Sherman 2003). In addition, penultimate acidic residues promote acetylation whereas basic residues inhibit it. The mouse $\mathrm{p} 19^{\text {Arf }}$ amino-terminal tripeptide, Met-Gly-Arg, is processed by methionine aminopeptidase, and the resulting Gly-Arg dipeptide strongly blocks acetylation, allowing amino-terminal ubiquitination. Arf mutants that were engineered to contain more favorable amino-terminal consensus sequences for acetylation were more stable than wild-type $\mathrm{p} 19^{\text {Arf }}$, indicating that amino-terminal ubiquitination can regulate the rate of Arf protein turnover (Kuo et al. 2004). In highmolecular-mass complexes with NPM, p19 ${ }^{\text {Arf }}$ may require ubiquitination for its unfolding and subsequent destruction, but unstable Arf mutants, although still subject to aminoterminal ubiquitination, may be less dependent on this process for their destruction.

\section{p53-INDEPENDENT FUNCTIONS OF Arf}

Despite cogent genetic arguments that $\mathrm{p} 19^{\mathrm{Arf}}$ has tumor suppressor activities that do not depend on Mdm2 and p53, the mechanism(s) underlying Arf's p53-independent functions remain unclear. Arf can physically or functionally interact with a variety of proteins, including the transcription factors E2F-1, Myc, NF-кB, and HIF$1 \alpha$, nucleolar proteins including NPM and nucleolin, topoisomerase I, the Werners helicase (WRN), cyclin G1, the adenovirus E1A-regulated transcriptional repressor $\mathrm{p} 120^{\mathrm{E} 4 \mathrm{~F}}$, and the HIV Tat-binding protein (Eymin et al. 2001; Martelli et al. 2001; Rocha et al. 2003; Zhao et al. 2003; Ayrault et al. 2004; Bertwistle et al. 2004a; Datta et al. 2004; Qi et al. 2004; Woods et al. 2004; Rizos et al. 2005). Although these interactions are of great potential interest, there are many caveats in interpreting their biological relevance. Most of these protein-protein interactions have been uncovered through antibody-mediated coprecipitation, frequently of overexpressed proteins. Because Arf is so highly basic and has a strong propensity to nonspecifically bind to nucleic acids and acidic proteins, it is difficult to devise appropriate experimental controls for such analyses. In many cases, mutagenesis has been employed to pinpoint domains within Arf and its target proteins that govern these interactions. However, a common finding has been that multiple segments within Arf and its associated proteins seem to contribute, thereby negating the possibility of identifying discrete motifs that direct specific binding. These problems are further compounded by observations that Arf mutants lacking particular segments are highly unstable or localize aberrantly when expressed in cells (see above).

Despite these difficulties, however, certain emerging themes merit strong consideration. Induction of p19 Arf can inhibit the production of ribosomal RNA by affecting the processing of $47 / 45 \mathrm{~S}$ and $32 \mathrm{~S}$ precursors (Sugimoto et al. 2003). These effects are not strictly dependent on inhibition of rRNA transcription, do not require $\mathrm{p} 53$, and are not mimicked by cell cycle arrest per se. Hence, p19 Arf may play a distinct role within the nucleolus, possibly in coordinating ribosome synthesis and cell growth (mass) with p53-dependent proliferative arrest.

Arf has also been demonstrated to inhibit gene expression through functional interactions with various transcription factors, including E2F-1 (Eymin et al. 2001; Martelli et al. 2001), NF-кB (Rocha et al. 2003), and Myc (Datta et al. 2004; Qi et al. 2004). Again, none of these effects depends on $\mathrm{p} 53$. There is some evidence that $\mathrm{p} 19^{\text {Arf }}$ can physically associate with E2F-1- and Myc-containing protein complexes (see above), but a direct interaction with NF-кB has not been reported. Overexpression of p19 Arf was found to accelerate E2F-1 degradation (Martelli et al. 2001), although this might potentially be due to an increase in E2F-1 turnover stemming from Arfinduced cell cycle arrest. In contrast, Arf has no apparent effect on Myc or NF- $\kappa \mathrm{B}$ protein levels.

By repressing the transcriptional activity of $\mathrm{NF}-\kappa \mathrm{B}$, ARF sensitizes cells to TNF $\alpha$-induced apoptosis (Rocha et al. 2003). In human cells responding to a conditionally regulated $A R F$ transgene, induction of $\mathrm{p} 14^{\mathrm{ARF}}$ was reported to trigger ATR- and Chk-1-dependent phosphorylation of the NF-кB RelA/p65 subunit on Thr-505, inhibiting its trans-activating function; ATR induction also resulted in p53 phosphorylation on Ser-15, a modification associated with p53 activation (Rocha et al. 2005). However, phosphorylation of RelA/p65, although dependent on ARF, ATR, and Chk1, was not observed when ATR 
and Chk1 were activated by UV irradiation, suggesting that $\mathrm{p} 14^{\mathrm{ARF}}$ is somehow required to target Chk1 kinase activity to specific substrates. Although ARF might conceivably activate ATR by interfering with DNA replication, ARF-expressing cells accumulate in $G_{1}$ and $G_{2}$ with very few cells remaining in $\mathrm{S}$ phase, and analysis of arrested cells with an antibody to $\gamma-\mathrm{H} 2 \mathrm{AX}$ revealed no increase in staining. The endogenous ATR protein was relocalized, together with BRCA1, to the nucleolus of ARF-expressing cells, and p14 ${ }^{\mathrm{ARF}}$ and ATR cofractionated in high-molecular-weight (>1 MD) complexes. In cells sustaining DNA damage, RPA binds single-stranded DNA and interacts with ATRIP to recruit ATR to stalled replication forks, but no RPA foci were observed in nucleoli following $\mathrm{p} 14^{\mathrm{ARF}}$ induction, again yielding no direct evidence for ARF-induced DNA damage. Hence, the manner by which $\mathrm{p} 14^{\mathrm{ARF}}$ engages the ATR-Chk1 kinase cascade remains unknown. This is a crucial issue, particularly because a recent report has indicated that various oncogenes that, on the one hand, can induce $A R F$ in precancerous lesions also induce DNA damage and activate the ATR/ATM and Chk kinases via ARF-independent signaling pathways (Bartkova et al. 2005).

Myc overexpression induces $\operatorname{Arf}$ (and can also damage DNA; Vafa et al. 2002), but, in turn, p19 ${ }^{\text {Arf }}$ can inhibit Myc function (Datta et al. 2004; Qi et al. 2004). One group of investigators reported that Myc binds directly to p19 ${ }^{\text {Arf }}$, relocalizing it from the nucleolus into the nucleoplasm (Qi et al. 2004). However, in other cell lines, p19 Arf appeared to localize Myc to the nucleolus (Datta et al. 2004). This is reminiscent of the Mdm2-Arf interaction in which overexpression of Arf localized Mdm2 to the nucleolus (Weber et al. 1999), whereas the opposite occurred when Mdm2 expression was enforced at high levels (Zhang and Xiong 1999). Many genes are activated by $\mathrm{Myc}$, and these include not only those transcribed by polymerase II, but also the pol-I-responsive rDNA clusters as well as the pol-III-driven genes encoding 5S RNA and tRNAs (Gomez-Roman et al. 2003; Orian et al. 2003; Grandori et al. 2005). Thus, Myc can be active within both the nucleoplasm and the nucleolus, and its relocalization between the two compartments in response to p19 Arf may not simply reflect an artifact of protein overexpression. A very interesting finding is that $\mathrm{p} 19^{\mathrm{Arf}} \mathrm{can}$ associate with Myc-Max complexes, antagonizing their trans-activating functions on certain promoters without impairing their transrepression of others (Qi et al. 2004). Myc binding to these promoters occurs whether or not p19 Arf (or p53) is present, so p19 Arf plays no role in recruiting Myc to chromatin but instead inhibits Myc's activator function in situ. Again, the underlying mechanisms remain unclear.

\section{Arf-INDUCED SUMOYLATION}

Surprisingly, the enforced expression of $\mathrm{p} 14^{\mathrm{ARF}}$ in human cells has been observed to promote the sumoylation of several cotransfected proteins, including $\mathrm{Hdm} 2$, the Werners helicase, E2F-1, and HIF-1 $\alpha$ (Xirodimas et al. 2002; Chen and Chen 2003; Woods et al. 2004; Rizos et al. 2005). Covalent addition of the small ubiquitin-like modifiers (SUMO 1, 2, and 3) to target proteins can generate diverse effects on protein transport, ubiquitination, DNA repair and chromatid adhesion, and on gene expression (usually, but not always, down-regulation) (Melchior 2000; Johnson 2004). Therefore, we speculate that the p53-independent activities of Arf might conceivably be due to this process.

Conjugation of SUMO to lysyl $\varepsilon$-amino groups in proteins occurs in a manner similar to ubiquitination (Johnson 2004). First, SUMO precursors must be cleaved by a protease to yield a carboxy-terminal diglycine motif. Processed SUMO is activated in an ATP-dependent manner by an E1 enzyme and transferred to a unique E2 conjugating enzyme (Ubc9), which can then affix SUMO to target proteins. The latter process can be accelerated by one of several E3 ligases that include the nucleoporin RanBP2 and a family of PIAS proteins (protein inhibitors of activated STATs) (Johnson and Gupta 2001; Sachdev et al. 2001; Pichler et al. 2002). SUMO-specific proteases assume a dual role in the cascade, being required for initial SUMO processing as well as the removal of SUMO from protein substrates (Hay 2001).

Sequences required for the efficient binding of $\mathrm{p} 14^{\mathrm{ARF}}$ or p19 ${ }^{\text {Arf }}$ to $(\mathrm{H}) \mathrm{Mdm} 2$, although differing between the human and mouse Arf proteins, are also necessary for sumoylation (Xirodimas et al. 2002; Tago et al. 2005). Endogenous NPM, to which Arf also binds, undergoes sumoylation in response to $\mathrm{p} 19^{\mathrm{Arf}}$ induction, but Arf did not trigger sumoylation of other known SUMO substrates with which it did not physically interact (Fig. 3) (Tago et al. 2005). The induction and accumulation of $\mathrm{p} 19^{\text {Arf }}$ leads to increased sumoylation within nucleoli; however, an

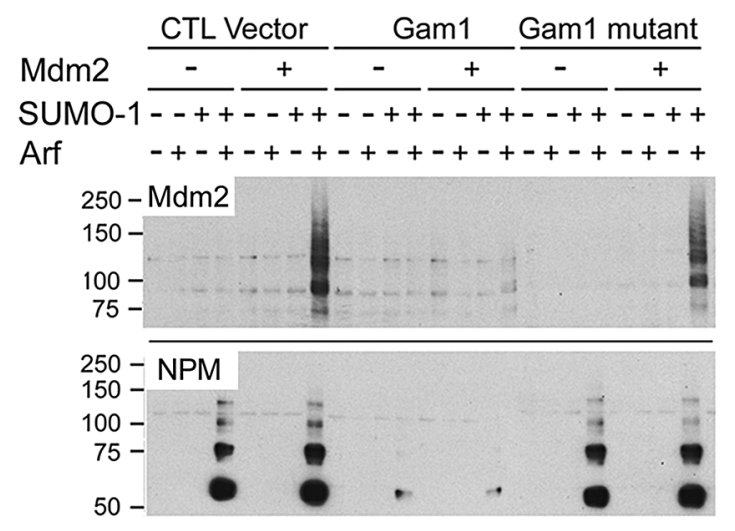

Figure 3. Arf induces sumoylation of Mdm2 and NPM. 293T cells were cotransfected with the combinations of expression vectors indicated at the top, which encoded Mdm2, His ${ }_{6}$-tagged SUMO-1, p19 ${ }^{\text {Arf }}$, and either a control retroviral expression vector or vectors encoding wild-type Gam 1 or a defective Gam1 mutant. Cellular proteins absorbed to nickel resin in the presence of $0.5 \mathrm{M} \mathrm{NaCl}$ and $8 \mathrm{M}$ urea were eluted with imidazole and sodium dodecyl sulfate, electrophoretically separated on denaturing gels, and blotted with antibodies to Mdm2 (upper panel) or NPM (lower panel). The fastest-migrating species in the lower panel corresponds to the monosumoylated endogenous NPM protein, whereas slower-migrating forms are multisumoylated. (Reprinted, with permission, from Tago et al. 2005.) 
Arf mutant that cannot efficiently enter nucleoli but still binds Mdm2 was defective in sumoylating it. Hence, Arfinduced sumoylation appears to depend on at least a transient association of $\mathrm{p} 19^{\text {Arf }}$ with its targets, and this may preferentially occur within the nucleolus where the major pool of $\mathrm{p} 19^{\text {Arf }}$ resides.

An avian adenoviral protein, Gam1, has the unique property of interfering with the SUMO E1 activating enzyme, a process that is accompanied by increased turnover of the SUMO E2, Ubc9 (Boggio et al. 2004). Either the introduction of Gam1 or shRNAs directed to Ubc9 can inhibit sumoylation within cells (Fig. 3). Although these manipulations ultimately prove toxic, inhibition of Arf-induced sumoylation of Mdm2 had no immediate effect on p53 stabilization or on the induction of canonical p53-responsive genes, such as Cipl or Mdm2 itself (Tago et al. 2005). Therefore, sumoylation appears not to be needed for activation of the p53 transcriptional program per se, although we cannot preclude more subtle effects.

An attractive idea is that Arf is a component of a SUMO E3 ligase and acts as a specificity factor that bridges Ubc9 complexes to Arf-binding proteins. SUMO-1 conjugation of the WRN helicase triggered by the SUMO E1 and E2 enzymes in vitro could not be accelerated by recombinant p14 ${ }^{\mathrm{ARF}}$ (Woods et al. 2004). This may not be surprising, given the "sticky" binding properties of recombinant Arf proteins and their propensity to misfold, so a better approach might be to purify native Arf-containing complexes from cells and test them for an associated E3 ligase activity when recombined with potential substrates and other purified components of the SUMO cascade.

Mammalian transcription factors that control cell proliferation are sumoylated (Hilgarth et al. 2004; Johnson 2004) and Gam 1 can increase promoter activation by several of them (Boggio et al. 2004). Gam1 reduces sumoylation of HDAC1 without affecting its enzymatic activity (Colombo et al. 2002), but its recruitment to promoters is enhanced when histone H4 is sumoylated (Shiio and Eisenman 2003). The fact that Arf can negatively regulate the transcriptional activities of E2F-1, NF- $\kappa B$, and $\mathrm{Myc}$ raises the question of whether sumoylation mediates these effects. Because the key elements of the SUMO cascade are highly conserved among all eukaryotes, it is reasonable to expect that Arf might induce sumoylationdependent phenotypes in other organisms that are more amenable to genetic dissection of this process.

\section{CONCLUSIONS}

From the time of its discovery, the properties of the Arf tumor suppressor have been surprising. The overlap of Arf and Ink $4 a$ gene sequences; the fact that the two gene products are both potent tumor suppressors that interact with p53 and $\mathrm{Rb}$, respectively; the notion that Arf responds to a select subset of oncogenic signals that induce p53; the highly basic nature of Arf proteins and their localization to nucleoli; the amino-terminal ubiquitination of Arf; and recent results implicating Arf in the process of sumoylation were all unexpected. Illuminating the vari- ous activities of Arf, and particularly its p53-independent functions, still poses a significant challenge.

\section{ACKNOWLEDGMENTS}

We thank the other members of the Sherr/Roussel laboratory, both past and present, for their suggestions and criticisms throughout the course of these studies. This work was supported in part by Cancer Center CORE Grant CA21765, by P01-CA71907 (M.F.R.), and by ALSAC of St. Jude Children's Research Hospital. C.J.S. is an investigator of the Howard Hughes Medical Institute.

\section{REFERENCES}

Adams J.M., Harris A.W., Pinkert C.A., Corcoran L.M., Alexander W.S., Cory S., Palmiter R.D., and Brinster R.L. 1985. The c-myc oncogene driven by immunoglobulin enhancers induces lymphoid malignancy in transgenic mice. Nature 318: 533.

Artandi S.E., Chang S., Lee S.L., Alson S., Gottlieb G.J., Chin L., and DePinho R.A. 2000. Telomere dysfunction promotes non-reciprocal translocations and epithelial cancers in mice. Nature 406: 573.

Aslanian A., Iaquinta P.J., Verona R., and Lees J.A. 2004. Repression of the Arf tumor suppressor by E2F3 is required for normal cell cycle kinetics. Genes Dev. 18: 1413.

Ayrault O., Andrique L., Larsen C.J., and Seite P. 2004. Human Arf tumor suppressor specifically interacts with chromatin containing the promoter of rRNA genes. Oncogene 23: 8097.

Bartkova J., Horejsi Z., Koed K., Kramer A., Tort F., Zieger K., Guldberg P., Sehested M., Nesland J.M, Lukas C., Orntoft T., Lukas J., and Bartek J. 2005. DNA damage response as a candidate anti-cancer barrier in early human tumorigenesis. $\mathrm{Na}$ ture 434: 864.

Bertwistle D., Sugimoto M., and Sherr C.J. 2004a. Physical and functional interactions of the Arf tumor suppressor protein with nucleophosmin/B23. Mol. Cell. Biol. 24: 985.

Bertwistle D., Zindy F., Sherr C.J., and Roussel M.F. 2004b. Monoclonal antibodies to the mouse $19^{\text {Arf }}$ tumor suppressor protein. Hybrid. Hybrid. 23: 293.

Blasco M.A., Lee H.-W., Hande M.P., Samper E., Lansdorp P.M., DePinho R.A, and Greider C.W. 1997. Telomere shortening and tumor formation by mouse cells lacking telomerase RNA. Cell 91: 25.

Boggio R., Colombo R., Hay R.T., Draetta G.F., and Chiocca S. 2004. A mechanism for inhibiting the SUMO pathway. Mol. Cell 16: 549.

Bradshaw R.A., Brickey W.W., and Walker K.W. 1998. N-terminal processing: The methionine aminopeptidase and $\mathrm{N}^{\alpha}$ acetyl transferase families. Trends Biochem. Sci. 23: 263.

Brady S.N., Yu Y., Maggi L.B., Jr., and Weber J.D. 2004. ARF impedes NPM/B23 shuttling in an Mdm2-sensitive tumor suppressor pathway. Mol. Cell. Biol. 24: 9327.

Busuttil R.A., Rubio M., Dolle M.E., Campisi J., and Vijg J. 2003. Oxygen accelerates the accumulation of mutations during the senescence and immortalization of murine cells in culture. Aging Cell 2: 287.

Carnero A., Hudson J.D., Price C.M., and Beach D.H. 2000. $\mathrm{p} 16^{\mathrm{INK} 4 \mathrm{a}}$ and $\mathrm{p} 19^{\mathrm{ARF}}$ act in overlapping pathways in cellular immortalization. Nat. Cell Biol. 2: 148.

Chen L. and Chen J. 2003. MDM2-ARF complex regulates p53 sumoylation. Oncogene 22: 5348.

Colombo R., Boggio R., Seiser C., Draetta G.F., and Chiocca S. 2002. The adenovirus protein Gam1 interferes with sumoylation of histone deacetylase I. EMBO Rep. 3: 1062.

Datta A., Nag A., Pan W., Hay N., Gartel A.L., Colamonici O., Mori Y., and Raychaudhuri P. 2004. Myc-ARF (alternative reading frame) interaction inhibits the functions of Myc. $J$. Biol. Chem. 279: 36698. 
De Stanchina E., McCurrach M.E., Zindy F., Shieh S.-Y., Ferbeyre G., Samuelson A.V., Prives C., Roussel M.F., Sherr C.J., and Lowe S.W. 1998. E1A signaling to p53 involves the p19 ${ }^{\mathrm{ARF}}$ tumor suppressor. Genes Dev. 12: 2434.

Eischen C.M., Weber J.D., Roussel M.F., Sherr C.J., and Cleveland J.L. 1999. Disruption of the ARF-Mdm2-p53 tumor suppressor pathway in Myc-induced lymphomagenesis. Genes Dev. 13: 2658.

El-Deiry W.S., Tokino T., Velculescu V.E., Levy D.B., Parsons R., Trent J.M., Lin D., Mercer E., Kinzler K.W., and Vogelstein B. 1993. WAF1, a potential mediator of p53 tumor suppression. Cell 75: 817 .

Eymin B., Karayan L., Seite P., Brambilla C., Brambilla E., Larsen C.J., and Gazzeri S. 2001. Human ARF binds E2F1 and inhibits its transcriptional activity. Oncogene 20: 1033.

Gil J., Bernard D., Martinez D., and Beach D. 2004. Polycomb CBX7 has a unifying role in cellular lifespan. Nat. Cell Biol. 6: 67 .

Gomez-Roman N., Grandori C., Eisenman R.N., and White R.J. 2003. Direct activation of RNA polymerase III transcription by c-Myc. Nature 421: 290.

Grandori C., Gomez-Roman N., Felton-Edkins Z.A., Ngouenet C., Galloway D.A., Eisenman R.N., and White R.J. 2005. c-Myc binds to human ribosomal DNA and stimulates transcription of rRNA genes by RNA polymerase I. Nat. Cell Biol. 7: 311.

Harvey D.M. and Levine A.J. 1991. p53 alteration is a common event in the spontaneous immortalization of primary BALB/c murine embryo fibroblasts. Genes Dev. 5: 2375.

Hay R.T. 2001. Protein modification by SUMO. Trends Biochem. Sci. 26: 332.

Hilgarth R.S., Murphy L.A., Skaggs H.S., Wilkerson D.C., Xing H., and Sarge K.D. 2004. Regulation and function of SUMO modification. J. Biol. Chem. 279: 53899.

Honda R. and Yasuda H. 1999. Association of $\mathrm{p} 19^{\mathrm{ARF}}$ with $\mathrm{Mdm} 2$ inhibits ubiquitin ligase activity of Mdm2 for tumor suppressor p53. EMBO J. 18: 22 .

Inoue K., Roussel M.F., and Sherr C.J. 1999. Induction of $A R F$ tumor suppressor gene expression and cell cycle arrest by transcription factor DMP1. Proc. Natl. Acad. Sci. 96: 3993.

Inoue K., Zindy F., Randle D.H., Rehg J.E., and Sherr C.J. 2001. Dmpl is haplo-insufficient for tumor suppression and modifies the frequencies of $A r f$ and $p 53$ mutations in $M y c$-induced lymphomas. Genes Dev. 15: 2934.

Inoue K., Wren R., Rehg J.E., Adachi M., Cleveland J.L., Roussel M.F., and Sherr C.J. 2000. Disruption of the ARF transcriptional activator $D M P 1$ facilitates cell immortalization, Ras transformation, and tumorigenesis. Genes Dev. 14: 1797.

Jacks T., Remington L., Williams B.O., Schmitt E.M., Halachmi S., Bronson R.T., and Weinberg R.A. 1994. Tumor spectrum analysis in p53-mutant mice. Curr. Biol. 4: 1.

Jacobs J.J.L., Kieboom K., Marino S., DePinho R.A., and van Lohuizen M. 1999a. The oncogene and Polycomb-group gene bmi- 1 regulates cell proliferation and senescence through the ink4a locus. Nature 397: 164

Jacobs J.J.L., Scheijen B., Vonchen J.-W., Kieboom K., Berns A., and van Lohuizen M. 1999b. Bmi-1 collaborates with cMyc in tumorigenesis by inhibiting c-Myc induced apoptosis via INK4a/ARF. Genes Dev. 13: 2678.

Jacobs J.J.L., Keblusek P., Robanus-Maandag E., Kristel P., Lingbeek M., Nederlof P.M., van Welsem T., van de Vijver M.J, Koh E.Y., Daley G.Q., and van Lohuizen M. 2000. Senescence bypass screen identifies TBX2, which represses $C d k n 2 a\left(p 19^{A R F}\right)$ and is amplified in a subset of human breast cancers. Nat. Genet. 26: 291.

Jerome-Majewska L.A., Jenkins G.P., Ernstoff E., Zindy F., Scherr C. J., and Papaioannou V.E. 2005. Tbx3, the ulnarmammary syndrome gene, and Tbx 2 interact in mammary gland development through a $\mathrm{p} 19 \mathrm{Arf} / \mathrm{p} 53$-independent pathway. Dev. Dynamics (in press).

Johnson E.S. 2004. Protein modification by SUMO. Annu. Rev. Biochem. 73: 355.

Johnson E.S. and Gupta A.A. 2001. An E3-like factor that promotes SUMO conjugation to the yeast septins. Cell 106: 735.

Kamijo T., Bodner S., van de Kamp E., Randle D.H., and Sherr
C.J. 1999a. Tumor spectrum in ARF-deficient mice. Cancer Res. 59: 2217

Kamijo T., van de Kamp E., Chong M.J., Zindy F., Diehl A.J., Sherr C.J., and McKinnon P. 1999b. Loss of the ARF tumor suppressor reverses premature replicative arrest but not radiation hypersensitivity arising from disabled Atm function. Cancer Res. 59: 2464.

Kamijo T., Zindy F., Roussel M.F., Quelle D.E., Downing J.R., Ashmun R.A., Grosveld G., and Sherr C.J. 1997. Tumor suppression at the mouse INK4a locus mediated by the alternative reading frame product $\mathrm{p} 19^{A R F}$. Cell 91: 649 .

Kelly-Spratt K.S., Gurley K.E., Yasui Y., and Kemp C.J. 2004. p19 Arf suppresses growth, progression, and metastasis of $\mathrm{H}$ ras-driven carcinomas through p53-dependent and -independent pathways. PLoS Biol. 2: 1138.

Kim S.H., Mitchell M., Fujii H., Llanos S., and Peters G. 2003. Absence of p16INK4a and truncation of ARF tumor suppressors in chickens. Proc. Natl. Acad. Sci. 100: 211.

Korgaonkar C., Hagen J., Tompkins V., Frazier A.A., Allamargot C., Quelle F.W., and Quelle D.E. 2005. Nucleophosmin (B23) targets ARF to nucleoli and inhibits its function. Mol. Cell. Biol. 25: 1258

Krimpenfort P., Quon K.C., Mooi W.J., Loonstra A., and Berns A. 2001. Loss of $p 16^{\text {Ink } 4 a}$ confers susceptibility to metastatic melanoma in mice. Nature 413: 83 .

Kuo M.-L., den Besten W., Bertwistle D., Roussel M.F., and Sherr C.J. 2004. N-terminal polyubiquitination and degradation of the Arf tumor suppressor. Genes Dev. 18: 1862.

Latres E., Malumbres M., Sotillo R., Martin J., Ortega S., Martin-Caballero J., Flores J.M., Cordon-Cardo C., and Barbacid M. 2000. Limited overlapping roles of P15(INK4b) and $\mathrm{P} 18$ (INK4c) cell cycle inhibitors in proliferation and tumorigenesis. EMBO J. 19: 3496.

Lee H.-W., Blasco M.A., Gottlieb G.J., Horber J.W., Greider C.W., and DePinho R.A. 1998. Essential role of mouse telomerase in highly proliferative organs. Nature 392: 569.

Lingbeek T., Jacobs J.J., and van Lohuizen M. 2002. The T-box repressors TBX2 and TBX3 specifically regulate the tumor suppressor gene $\mathrm{p} 14 \mathrm{ARF}$ via a variant $\mathrm{T}$-site in the initiator. J. Biol. Chem. 277: 26120.

Llanos S., Clark P.A., Rowe J., and Peters G. 2001. Stabilization of $\mathrm{p} 53$ by p14ARF without relocation of MDM2 to the nucleolus. Nat. Cell Biol. 3: 445 .

Lowe S.W. and Sherr C.J. 2003. Tumor suppression by Ink4aArf: Progress and puzzles. Curr. Opin. Genet. Dev. 13: 77.

Maeda T., Hobbs R.M., Merghoub T., Guernah I., Zelent A., Cordon-Cardo C., Teruya-Feldstein J., and Pandolfi P.P. 2005. Role of the proto-oncogene Pokemon in cellular transformation and ARF repression. Nature 433: 278.

Maestro R., Dei Tos A.P., Hamamori Y., Krasnokutsky S., Sartorelli V., Kedes L., Doglioni C., Beach D., and Hannon G.J. 1999. Twist is a potential oncogene that inhibits apoptosis. Genes Dev. 13: 2207.

Martelli F., Hamilton T., Silver D.P., Sharpless N.E., Bardeesy N., Rokas M., DePinho R.A., Livingston D.M., and Grossman S.R. 2001. p19ARF targets certain E2F species for degradation. Proc. Natl. Acad. Sci. 98: 4455.

McKeller R.N., Fowler J.L., Cunningham J.J., Warner N., Smeyne R.J., Zindy F., and Skapek S.X. 2002. The Arf tumor suppressor gene promotes hyaloid vascular regression during mouse eye development. Proc. Natl. Acad. Sci. 99: 3848.

Melchior F. 2000. SUMO - Nonclassical ubiquitin. Annu. Rev. Cell Dev. Biol. 16: 591.

Modestou M., Puig-Antich V., Korgaonkar C., Eapen A., and Quelle D.E. 2001. The alternative reading frame tumor suppressor inhibits growth through p21-dependent and p21-independent pathways. Cancer Res. 61: 3145 .

Orian A., van Steensel B., Delrow J., Bussemaker H.J., Li L., Sawado T., Williams E., Loo L.W., Cowley S.M., Yost C., Pierce S., Edgar B.A, Parkhurst S.M., and Eisenman R.N. 2003. Genomic binding by the Drosophila Myc, Max, $\mathrm{Mad} / \mathrm{Mnt}$ transcription factor network. Genes Dev. 17: 1101.

Ortega S., Malumbres M., and Barbacid M. 2002. Cyclin D-dependent kinases, INK4 inhibitors, and cancer. Biochim. Bio- 
phys. Acta 1602: 73

Palmero I., Pantoja C., and Serrano M. 1998. p19 ${ }^{\text {ARF }}$ links the tumour suppressor p53 to Ras. Nature 395: 125.

Pantoja C. and Serrano M. 1999. Murine fibroblasts lacking $p 21$ undergo senescence and are resistant to transformation by oncogenic Ras. Oncogene 18: 4974.

Parrinello S., Samper E., Krtolica A., Goldstein J., Melov S., and Campisi J. 2003. Oxygen sensitivity severely limits the replicative lifespan of murine fibroblasts. Nat. Cell Biol. 5: 741.

Pichler A., Gast A., Seeler J.S., Dejean A., and Melchior F. 2002. The nucleoporin RanBP2 has a SUMO1 E3 ligase activity. Cell 108: 109.

Polevoda B. and Sherman F. 2003. N-terminal acetyltransferases and sequence requirements for $\mathrm{N}$-terminal acetylation of eukaryotic proteins. J. Mol. Biol. 325: 595 .

Qi Y., Gregory M.A., Li Z., Brousal J.P., West K., and Hann S.R. 2004. p19ARF directly and differentially controls the functions of c-Myc independently of p53. Nature 431: 712.

Quelle D.E., Cheng M., Ashmun R.A., and Sherr C.J. 1997. Cancer-associated mutations at the INK4a locus cancel cell cycle arrest by p16INK4a but not by the alternative reading frame protein p19ARF. Proc. Natl. Acad. Sci. 94: 669.

Quelle, D.E., Zindy F., Ashmun R.A., and Sherr C.J. 1995. Alternative reading frames of the INK4a tumor suppressor gene encode two unrelated proteins capable of inducing cell cycle arrest. Cell 83: 993.

Randle D.H., Zindy F., Sherr C.J., and Roussel M.F. 2001. Differential effects of $\mathrm{p} 19^{\text {Arf }}$ and $\mathrm{p} 16^{\text {Ink4a }}$ loss on senescence of murine bone marrow-derived pre-B cells and macrophages. Proc. Natl. Acad. Sci. 98: 9654.

Rizos H., Woodruff S., and Kelford R.F. 2005. p14ARF interacts with the SUMO-conjugating enzyme Ubc9 and promotes the sumoylation of its binding partners. Cell Cycle 4: e39.

Rocha S., Campbell K.J., and Perkins N.D. 2003. p53- and Mdm2-independent repression of NF- $\mathrm{BB}$ transactivation by the ARF tumor suppressor. Mol. Cell 12: 15.

Rocha S., Garrett M.D., Campbell K.J., Schumm K., and Perkins N.D. 2005. Regulation of NF- $\kappa$ B and p53 through activation of ATR and Chk1 by the ARF tumour suppressor. EMBO J. 24: 1157

Roussel M.F. 1999. The INK4 family of cell cycle inhibitors in cancer. Oncogene 18: 5311.

Rowland B.D., Denissov S.G., Douma S., Stunnenberg H.G., Bernards R., and Peepers D.S. 2002. E2F transcriptional repressor complexes are critical downstream targets of p19 $19^{\mathrm{ARF}} / \mathrm{p} 53$-induced proliferative arrest. Cancer Cell 2: 55.

Ruas M. and Peters G. 1998. The $16^{\mathrm{INK} 4 \mathrm{a}} / \mathrm{CDKN} 2 \mathrm{~A}$ tumor suppressor and its relatives. Biochim Biophys. Acta 1378: F115.

Rudolph K.L., Chang S., Lee H.W., Blasco M., Gottlieb G.J., Greider C., and DePinho R.A. 1999. Longevity, stress response, and cancer in aging telomerase-deficient mice. Cell 96: 701.

Sachdev S., Bruhn L., Sieber H., Pichler A., Melchior F., and Grosschedl R. 2001. PIASy, a nuclear matrix-associated SUMO E3 ligase, represses LEF1 activity by sequestration into nuclear bodies. Genes Dev. 15: 3088.

Schmitt C.A., McCurrach M.E., De Stanchina E., and Lowe S.W. 1999. INK4a/ARF mutations accelerate lymphomagenesis and promote chemoresistance by disabling p53. Genes Dev. 13: 2670.

Serrano M., Hannon G.J., and Beach D. 1993. A new regulatory motif in cell cycle control causing specific inhibition of cyclin D/CDK4. Nature 366: 704.

Serrano M., Lee H.-W., Chin L., Cordon-Cardo C., Beach D., and DePinho R.A. 1996. Role of the INK4a locus in tumor suppression and cell mortality. Cell 85: 27.

Sharpless N.E., Bardeesy N., Lee K.-H., Carrasco D., Castrillon D.H., Aguirre A.J., Wu E.A., Horner J.W., and DePinho R.A. 2001. Loss of $\mathrm{p} 16^{\mathrm{Ink} 4 \mathrm{a}}$ with retention of $\mathrm{p} 19^{\mathrm{Arf}}$ predisposes mice to tumorigenesis. Nature 413: 86.
Sherr C.J. 1998. Tumor surveillance via the ARF-p53 pathway. Genes Dev. 12: 2984.

Sherr C.J. and DePinho R.A. 2001. Cellular senescence: Mitotic clock or culture shock. Cell 102: 407.

Shiio Y. and Eisenman R.N. 2003. Histone sumoylation is associated with transcriptional repression. Proc. Natl. Acad. Sci. 100: 13118 .

Smogorzewska A. and De Lange T. 2002. Different telomere damage signaling pathways in human and mouse cells. EMBO J. 21: 4338.

Sreeramaneni R., Chaudhry A., McMahon M., Sherr C.J., and Inoue K. 2005. Ras-Raf-Arf signaling critically depends on the Dmp1 transcription factor. Mol. Cell. Biol. 25: 220.

Sugimoto M., Kuo M.L., Roussel M.F., and Sherr C.J. 2003. Nucleolar Arf tumor suppressor inhibits ribosomal RNA processing. Mol. Cell 11: 415.

Tago K., Chiocca S., and Sherr C.J. 2005. Sumoylation induced by the Arf tumor suppressor: A p53-independent function. Proc. Natl. Acad. Sci. 102: 7689.

Vafa O., Wade M., Kern S., Beeche M., Pandita T.K., Hampton G.M., and Wahl G.M. 2002. c-Myc can induce DNA damage, increase reactive oxygen species, and mitigate $\mathrm{p} 53$ function: A mechanism for oncogene-induced genetic instability. Mol. Cell 9: 1031.

Vousden K.H. and Lu X. 2002. Live or let die: The cell's response to p53. Nat. Rev. Cancer 2: 594.

Weber J.D., Taylor L.J., Roussel M.F., Sherr C.J., and Bar-Sagi D. 1999. Nucleolar Arf sequesters Mdm2 and activates p53. Nat. Cell Biol. 1: 20.

Weber J.D., Kuo M.-L., Bothner B., DiGiammarino E.L., Kriwacki R.W., Roussel M.F., and Sherr C.J. 2000a. Cooperative signals governing ARF-Mdm2 interaction and nucleolar localization of the complex. Mol. Cell. Biol. 20: 2517.

Weber J.D., Jeffers J.R., Rehg J.E., Randle D.H., Lozano G., Roussel M.F., Sherr C.J., and Zambetti G.P. 2000b. p53-independent functions of the $19^{\mathrm{ARF}}$ tumor suppressor. Genes Dev. 14: 2358.

Weitzman J.B., Fiette L., Matsuo K., and Yaniv M. 2000. JunD protects cells from p53-dependent senescence and apoptosis. Mol. Cell 6: 1109.

Woods Y.L., Xirodimas D.P., Prescott A.R., Sparks A., Lane D.P., and Saville M.K. 2004. p14ARF promotes small ubiquitin-like modifier conjugation of Werners helicase. J. Biol. Chem. 279: 50157.

Wright W.E. and Shay J.W. 2000. Telomere dynamics in cancer progression and prevention: Fundamental differences in human and mouse telomere biology. Nat. Med. 6: 849 .

Xirodimas D.P., Chisholm J., Desterro J.M.S., Lane D.P., and Hay R.T. 2002. p14ARF promotes accumulation of SUMO-1 conjugated (H)Mdm2. FEBS Lett. 528: 207.

Zhang Y. and Xiong Y. 1999. Mutations in human ARF exon 2 disrupt its nucleolar localization and impair its ability to block nuclear export of MDM2 and p53. Mol. Cell 3: 579.

Zhao L., Samuels T., Winckler S., Korgaonkar C., Tompkins V., Horne M.C, and Quelle D.E. 2003. Cyclin G1 has growth inhibitory activity linked to the ARF-Mdm2-p53 and pRb tumor suppressor pathways. Mol. Cancer Res. 1: 195.

Zindy F., Quelle D.E., Roussel M.F., and Sherr C.J. 1997. Expression of the $16^{\mathrm{INK} 4 \mathrm{a}}$ tumor suppressor versus other INK4 family members during mouse development and aging. Oncogene 15: 203.

Zindy F., Eischen C.M., Randle D.H., Kamijo T., Cleveland J.L., Sherr C.J., and Roussel M.F. 1998. Myc signaling via the ARF tumor suppressor regulates p53-dependent apoptosis and immortalization. Genes Dev. 12: 2424.

Zindy F., Williams R.T., Baudino T.A., Rehg J.E, Skapek S.X., Cleveland J.L., Roussel M.F., and Sherr C.J. 2003. Arf tumor suppressor promoter monitors latent oncogenic signals in vivo. Proc. Natl. Acad. Sci. 100: 15930. 


\title{
$\$_{\text {CSH\& }}^{\infty} \mathrm{Cold}$ Spring Harbor Symposia SYMPOSIA on Quantitative Biology
}

\section{p53-Dependent and -Independent Functions of the Arf Tumor Suppressor}

\author{
C.J. SHERR, D. BERTWISTLE, W. DEN BESTEN, et al.
}

Cold Spring Harb Symp Quant Biol 2005 70: 129-137

Access the most recent version at doi:10.1101/sqb.2005.70.004

References This article cites 99 articles, 42 of which can be accessed free at: http://symposium.cshlp.org/content/70/129.full.html\#ref-list-1

License

Email Alerting Receive free email alerts when new articles cite this article - sign up in Service the box at the top right corner of the article or click here. 